* Artigo Original

\title{
Facilitadores e barreiras à utilização das teleconsultorias off- line: a experiência dos médicos da atenção primária de Belo Horizonte
}

\section{Sandra Silva Mitraud Ruas}

Secretaria Municipal de Saúde de Belo Horizonte. Mestre em Saúde Pública pela Faculdade de Medicina da Universidade Federal de Minas Gerais, Médica Sanitarista da Gerência de Tecnologia e Informação em Saúde da Secretaria Municipal de Saúde de Belo Horizonte. sandramitraud@bol.com.br

\begin{abstract}
Ada Ávila Assunção
Universidade Federal de Minas Gerais. Professora Associada na Faculdade de Medicina da UFMG e orientadora de iniciação científica, especialização, mestrado e doutorado, sendo permanente no Programa de Pós-Graduação em Saúde Pública na área saúde e trabalho. adavila@medicina.ufmg.br
\end{abstract}

DOI: $10.3395 /$ reciis.v7i1.593pt

\section{Resumo}

INTRODUÇÃO: Telessaúde é a prestação de serviços de saúde por profissionais que utilizam as tecnologias de informação e comunicação para intercâmbio de informações para fins de diagnóstico, tratamento e prevenção de doenças, processos de educação em saúde, pesquisas e avaliações. Objetivo foi identificar facilitadores e barreiras à sua incorporação na rotina de trabalho. METODOS: A amostra intencional incluiu 2 homens e 5 mulheres de diferentes distritos sanitários que fizeram uso de teleconsultorias off line. Entrevistas individuais e análise de conteúdo foram realizadas. Após a leitura flutuante dos textos das entrevistas, foram identificados os trechos correspondentes a cada uma das categorias e subcategorias do modelo explicativo baseado na Teoria da Difusão. RESULTADOS: A teleconsultoria off line é considerada de fácil utilização, promove o aperfeiçoamento e reforça o vínculo médicopaciente. Os médicos solicitantes afirmam o potencial e a pertinência da teleconsultoria off line para a atenção primária à saúde. Os entraves (sobrecarga de trabalho, debilidades no treinamento e pouca familiaridade do profissional com a informática) interagem para influenciar a decisão de utilização. CONCLUSÃO: Baixa taxa de utilização e as contradições encontradas sugerem pistas para orientar a gestão em suas ações visando à consolidação do sistema.

Palavras-chave: Telemedicina; Telessaúde; Consulta remota; Atenção primária à saúde; Teleconsultoria.

\section{Introdução}

O uso de tecnologias da informação e comunicação (TIC) para intercâmbio de conhecimento no setor saúde foi recomendado pela Organização Pan-Americana de Saúde (OPAS, 2010) como 
uma estratégia de desenvolvimento de competências dos profissionais a fim de assegurar a renovação da atenção primária à saúde (APS), a operação de redes integradas de serviços e o desempenho adequado das funções essenciais de saúde pública.

A telessaúde é uma ferramenta para apoiar a prestação de serviços de saúde e discutir com o profissional assistente uma solução potencial para alguns problemas vivenciados no âmbito da assistência e da gestão dos sistemas de saúde. Caracteriza-se pelo uso de TIC para fins assistenciais, administrativos, educacionais e de pesquisa em saúde. A tendência dos sistemas de saúde a oferecer o máximo de serviços e o mínimo de deslocamentos explica, em parte, a rápida expansão na aplicação de recursos de telessaúde em escala mundial. Trata-se de uma inovação com potencial para induzir mutações nas práticas de trabalho e nas estruturas organizacionais dos serviços de saúde (GAGNON et al., 2005).

Em Belo Horizonte implantou-se, em 2004, o BHTelessaúde destinado claramente a sustentar a APS em seus objetivos de longitudinalidade e continuidade. O modelo da APS preconiza que o médico assuma a responsabilidade de tomar, em conjunto com os colegas de equipe, as primeiras decisões diante dos problemas que se apresentam, requerendo a participação de especialistas quando julgar conveniente. Esse processo dinâmico oferece continuidade e longitudinalidade, ou seja, viabiliza o seguimento dos problemas concretos de saúde e o acompanhamento da pessoa (BRASIL, 2006).

As TICs beneficiariam a longitudinalidade e continuidade ao facilitar a coordenação dos cuidados e a tomada de decisão pelo médico da APS que contou com o apoio do especialista para dirimir as suas dúvidas (GAGNON et al., 2006). No conjunto, os ganhos favorecem a qualidade dos serviços ao facilitar a criação e manutenção do vínculo paciente-equipe de saúde (GÉRVAS; ORTÚN, 1995).

Em Belo Horizonte, a implantação da teleconsultoria off-line teve como finalidade prover um canal de comunicação entre os profissionais da APS e os especialistas dos níveis secundários de atenção da rede municipal de saúde e da Universidade Federal de Minas Gerais (UFMG). Trata-se de um recurso de telessaúde que garante o suporte assistencial ao mesmo tempo em que se constitui um instrumento de educação continuada voltado para os problemas concretos da APS.

Contudo, a difusão da telessaúde como um componente integral do sistema de saúde representa um grande desafio (GAGNON et al., 2006). Em estudo anterior (RUAS, 2012), registraram-se taxas de utilização de 6,0\% (2008, n=861), 4,8\% (2009, n=960), e 1,2\% (2010, $\mathrm{n}=1180) ; 85$ médicos num universo de aproximadamente 1.000 médicos (média entre 2008, 2009 e 2010) utilizaram o serviço de teleconsultoria off-line ; o número de teleconsultorias off-line realizadas por médico variou de um a 114 após a implantação do BHTelessaúde; a utilização não foi homogênea entre os distritos sanitários. Diante de tais resultados, a construção metodológica e seus instrumentos, que neste artigo assentam-se na perspectiva qualitativa, buscou responder às seguintes questões: Seria plausível supor que os médicos não estariam suficientemente treinados para usar a teleconsultoria off-line? Quais são os significados e práticas do uso de teleconsultorias off-line nas Unidades Básicas de Saúde (UBS) de Belo Horizonte?

Diferentes fatores podem explicar a baixa utilização e as discrepâncias encontradas, incluindo as especificidades do ambiente e o contexto sociopolítico, as características das organizações e 
dos fatores individuais associados às dimensões individuais dos agentes em que a telessaúde foi implantada (GAGNON et al., 2006). Diante de tais pressupostos, o objetivo deste estudo foi identificar os facilitadores e barreiras vivenciadas pelos médicos no uso das teleconsultorias off-line nas UBS de Belo Horizonte.

\section{Estratégia metodológica}

Realizou-se pesquisa qualitativa utilizando-se a técnica de entrevista individual semidirigida com questões abertas. A amostra foi composta de médicos da atenção primária que utilizaram teleconsultorias off-line (TLC) no período 2006-2010.

A abordagem qualitativa é indicada quando a investigação se interessa em compreender as atitudes dos sujeitos, porque possibilita capturar o significado que eles constroem em torno de suas experiências (TRIVIÑOS, 1987).

A entrevista é o instrumento primordial de coleta de dados na pesquisa qualitativa, uma vez que os significados se manifestam pela linguagem (LÜDKE; ANDRÉ, 1986). A técnica utilizada, comparada à entrevista estruturada, tem menos validade, por outro lado, ganha-se em profundidade (MACHADO, 2002).

Durante a entrevista semidirigida, utilizando-se as questões abertas do roteiro que foi preparado para os fins específicos da pesquisa, a entrevistadora introduzia um tópico e o sujeito livremente expressava as suas respostas. Assim, não houve delimitação de alternativas de respostas. A condução da entrevista foi suficientemente flexível para propiciar a ocorrência de situações como permitir ao entrevistado prosseguir numa ordem diversa da estabelecida no roteiro, de maneira a não impedir o desenvolvimento espontâneo de um tópico. A flexibilidade na condução permitiu o surgimento de questões que, apesar de atinentes ao tema, não estavam contempladas no roteiro prévio. A escuta tentou estimular o fluxo de informações sem, contudo, forçar respostas em determinada direção (LÜDKE; ANDRÉ, 1986; TURATO, 2003). Tal flexibilidade é fundamental para garantir o desejado aprofundamento e o enriquecimento do tema (TURATO, 2003).

O estudo foi aprovado pelos Comitês de Ética em Pesquisa da UFMG e da Secretaria Municipal de Saúde de Belo Horizonte (SMSA) e realizado no período de 2010 a 2011. Para garantir o sigilo e a confidencialidade das informações, os dados coletados foram registrados de maneira a impedir a identificação dos participantes. A pesquisa não contou com nenhum financiamento e os autores declaram que não há conflito de interesses.

\section{As entrevistas individuais e semidirigidas}

Adotando-se os critérios coerentes aos objetivos da pesquisa, foi obtida a amostra de sete sujeitos, médicos de UBS que fizeram uso das TLCs.

Vale salientar que a amostragem em estudos qualitativos não segue os princípios de aleatoriedade e de representação estatística usualmente empregados nos estudos quantitativos (TURATO, 2003). Ao contrário, no quadro da presente pesquisa destaca-se a relevância dos aspectos subjetivos que explicariam a utilização ou não das TLCs e que dificilmente seriam apreendidos por questionários e quantificação de variáveis conhecidas de antemão. As investigações qualitativas se interessam pelas particularidades, por isso a ênfase nos casos ou depoimentos exemplares de determinada situação (GOLDENBERG, 2007). 
Em suma, o número de pessoas é menos importante do que a profundidade que a técnica utilizada permite assimilar a partir das vivências dos sujeitos-alvo (TURATO, 2003). Na pesquisa qualitativa a representatividade dos dados está relacionada à sua capacidade de enxergar uma situação sob várias perspectivas e não à sua expressividade numérica (GOLDENBERG, 2007). Por tal razão, a seleção dos sujeitos da amostra não se dá por conveniência, mas sim por critérios previamente estabelecidos, devidamente justificados no projeto de pesquisa.

Inicialmente foram elaborados os critérios de inclusão/exclusão visando à seleção de médicos passíveis de utilização das TLCs. Em seguida, buscou-se diversificar a amostra de maneira a evitar concentração dos sujeitos em uma UBS ou distrito sanitário. Adotando-se tais critérios, obteve-se um grupo representativo quanto às experiências no tocante ao uso das TLCS (solicitantes frequentes ou eventuais) e diverso o bastante para permitir aflorar as semelhanças, as ambiguidades e os contrastes.

Seguindo tais princípios, a amostra contemplou homens e mulheres inseridos em diferentes distritos sanitários que fizeram algum uso de TLC. Segundo estudo anterior (RUAS, 2012) o total de médicos potencialmente usuários de TLCs, de acordo com média anual obtida para os anos de 2008, 2009 e 2010, é de aproximadamente 1000, e o total de médicos solicitantes no período $2006-2010$ foi de 85 .

Tendo em vista a distribuição do total de médicos solicitantes de TLC (85) no período do estudo (RUAS, 2012), viu-se que oito deles (9,4\% do total de solicitantes) foram responsáveis por $50,9 \%$ do total de TLCs realizadas (p. 42). Cada um desses oito médicos solicitantes realizou mais de 20 TLCs e foram considerados solicitantes frequentes. Os demais (77) solicitaram menos de 20 TLCs e foram considerados solicitantes eventuais.

De ambos os grupos, identificaram-se aqueles que fizeram uso recente (nos 12 meses anteriores à data das entrevistas), a fim de reduzir a ocorrência do viés de memória. Esse critério resultou na identificação de seis médicos solicitantes frequentes distribuídos em três distritos sanitários (quatro no Distrito Centro-Sul, um no Distrito Oeste e um em Venda Nova) e oito solicitantes eventuais (um no Distrito Centro-Sul, cinco na Noroeste, um no Barreiro e um na Pampulha).

Do primeiro grupo selecionou-se um indivíduo de cada distrito, sendo que o eleito do Distrito Centro-Sul foi o médico com mais alto número de TLCs realizadas no período do estudo. Igualmente, do segundo grupo, selecionou-se um indivíduo de cada distrito, sendo que no Distrito Noroeste foi eleito um solicitante do sexo masculino. Sexo é uma variável individual sabidamente relacionada à utilização de tecnologias (GAGNON et al., 2010) e, portanto, seria importante evitar uma amostra essencialmente feminina, apesar de sua maioria entre os médicos solicitantes (RUAS, 2012). O usuário representante do Distrito Barreiro, apesar de selecionado pelos critérios de inclusão/exclusão, abandonou o vínculo com a UBS, tendo sido excluído da amostra.

A fim de contemplar a lógica gerencial, adicionou-se um médico, solicitante de TLC, que ocupa a função de gerente de UBS, pois os fatores normativos também interferem na utilização de tecnologias. Sabe-se que a atitude gerencial pode favorecer ou criar barreiras às mudanças e desenvolvimento das atividades profissionais (CLARK; GOODWIN, 2010; ROGERS, 2003). Esse processo descrito está representado na Figura 1. 


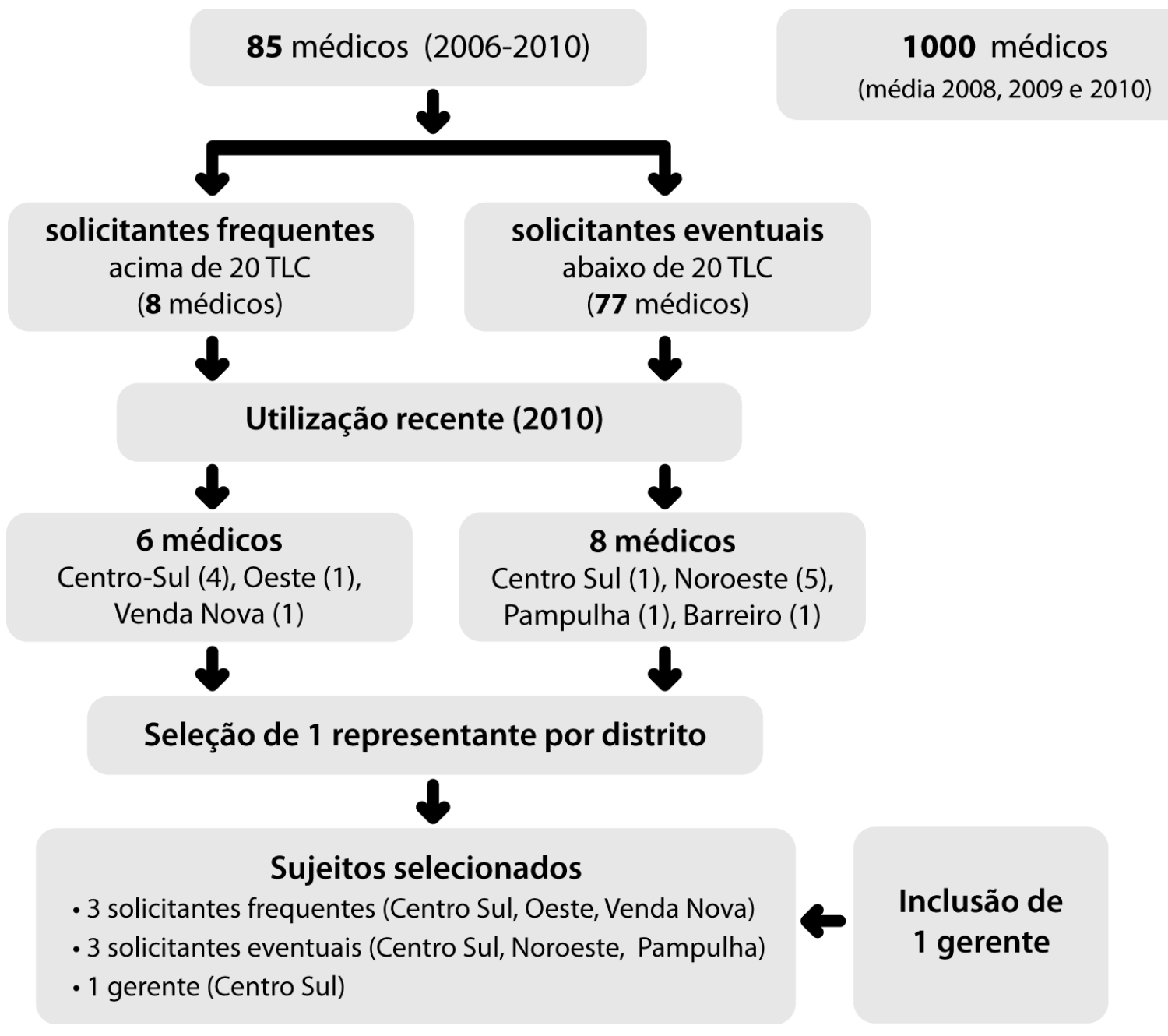

Figura 1 - Esquema representativo do processo de seleção dos sujeitos

Todos os sujeitos selecionados aceitaram participar do estudo e assinaram o Termo de Consentimento Livre e Esclarecido.

\section{A análise de conteúdo}

A análise de conteúdo ( $A C)$ é um conjunto de técnicas de análise das comunicações que visa obter, por meio de procedimentos sistemáticos e objetivos, indicadores (quantitativos ou não) que permitem inferir conhecimento sobre as condições de produção dessas mensagens (BARDIN, 1977).

A técnica de análise por categorias busca encontrar os significados presentes nas mensagens por meio do desmembramento do texto em unidades e seu posterior reagrupamento em função de características comuns (CAREGNATO, MUTTI; 2006).

Para a análise das entrevistas foram elaboradas categorias temáticas visando conhecer as vivências dos médicos no uso da TLC e identificar tanto dificuldades quanto benefícios alcançados.

A análise foi orientada pelas teorias de Rogers (2003), Davis (1989) e Karahanna, Straub e Chervany (KARAHANNA; STRAUB; CHERVANY, 1999), as quais buscam explicar os 
comportamentos dos indivíduos submersos em ambientes nos quais é possível fazer uso de uma tecnologia ou de uma inovação.

A difusão de uma inovação é o processo pelo qual a inovação é transmitida por meio de certos canais e ao longo do tempo aos indivíduos de um sistema social. Tal processo envolve as seguintes etapas: conhecimento de uma inovação existente, formação de atitude favorável à adoção, decisão de adotar, implementação/uso e confirmação da adoção (ROGERS, 2003).

O Modelo da Aceitação de Tecnologia (DAVIS, 1989) pressupõe que a aceitação de tecnologia é determinada por duas crenças principais: a facilidade de utilização percebida e a utilidade percebida. Facilidade percebida é o grau com que uma pessoa acredita que o uso do sistema será livre de esforço. Utilidade percebida é grau com que se acredita que o uso do sistema aumentará seu desempenho. Aceitação de tecnologia refere-se à intenção individual de se usar ou o uso voluntário.

O Modelo de Adoção e Utilização Continuada (KARAHANNA; STRAUB; CHERVANY, 1999) combina aspectos da Teoria da Difusão, percepções individuais e incorpora a dimensão tempo. Segundo os autores, os determinantes da adoção variam ao longo do tempo: nas fases iniciais, as normas institucionais têm mais peso na decisão de se adotar a tecnologia (influência do contexto, apoio da gestão de topo, atitude gerencial); nas fases subsequentes, as percepções a respeito dos atributos da inovação, os resultados alcançados com o uso e o grau de controle do indivíduo sobre suas tarefas (voluntariedade do utilizador) seriam mais importantes na decisão de continuar usando.

Associando-se esses três modelos e agregando outras contribuições da literatura (BERGOUHT et al., 2007; CLARK; GOODWIN, 2010; MARTINEZ, 2000; YARBROGH; SMITH, 2007), foi elaborado um modelo explicativo do processo de aceitação e difusão de aplicações de telessaúde (Quadro 1). 


\section{Pressupostos}

- O processo de inovação inicia-se com a identificação da necessidade de mudança.

- Introduzida a inovação, é preciso transmiti-la por meio de certos canais aos indivíduos do sistema para que os mesmos formem uma atitude favorável ao uso.

- Ocorrendo a intenção de usar, o indivíduo necessitará dispor das condições necessárias ao uso.

- Por fim, a experimentação propiciará a confirmação ou rejeição da adoção.

\begin{tabular}{|c|c|}
\hline \multicolumn{2}{|r|}{ Categorias e subcategorias de análise } \\
\hline $\begin{array}{l}\text { Atributos da } \\
\text { inovação }\end{array}$ & $\begin{array}{l}\text { Utilidade, complexidade (usabilidade), vantagem relativa, } \\
\text { compatibilidade da inovação com as crenças e valores dos } \\
\text { indivíduos do sistema social, possibilidade de experimentação } \\
\text { (ROGERS, 2003; DAVIS, 1989); tempo requerido no uso } \\
\text { (GAGNON et al., 2010; BERGOUHT et al., 2007; KARAHANNA; } \\
\text { STRAUB; CHERVANY, 1999), interoperabilidade com outros } \\
\text { softwares em uso (GAGNON et al.., 2010; CLARK; GOODWIN, } \\
\text { 2010; YARBROGH; SMITH, 2007; ROGERS, 2003). }\end{array}$ \\
\hline $\begin{array}{l}\text { Aspectos da } \\
\text { implantação }\end{array}$ & $\begin{array}{l}\text { Tipo de decisão, canais utilizados na divulgação, agentes } \\
\text { promotores da mudança (ROGERS, 2003), treinamento } \\
\text { (YARBROGH; SMITH, 2007; ROGERS, 2003). }\end{array}$ \\
\hline $\begin{array}{l}\text { Aspectos } \\
\text { organizacionais }\end{array}$ & $\begin{array}{l}\text { Normas e institucionalização das atividades relacionadas a } \\
\text { inovação, sobrecarga de trabalho, compatibilidade da inovação } \\
\text { com o processo de trabalho, organização das tarefas, presença } \\
\text { de usuários formadores de opinião (GAGNON et al., 2010); } \\
\text { apoio do gerente local (MARTINEZ, 2000). }\end{array}$ \\
\hline $\begin{array}{l}\text { Aspectos } \\
\text { individuais }\end{array}$ & $\begin{array}{l}\text { Familiaridade com a tecnologia, idade, experiência, sexo, } \\
\text { especialidade, crenças e valores em relação à tecnologia, } \\
\text { relação médico-paciente (GAGNON et al., 2010). }\end{array}$ \\
\hline $\begin{array}{l}\text { Condições de } \\
\text { trabalho }\end{array}$ & $\begin{array}{l}\text { Recursos materiais, funcionamento adequado do sistema e } \\
\text { suporte técnico (GAGNON et al., 2010). }\end{array}$ \\
\hline $\begin{array}{l}\text { Satisfação no } \\
\text { uso }\end{array}$ & $\begin{array}{l}\text { Qualidade científica das orientações e benefícios proporcionados } \\
\text { (GAGNON et al., 2010). }\end{array}$ \\
\hline
\end{tabular}




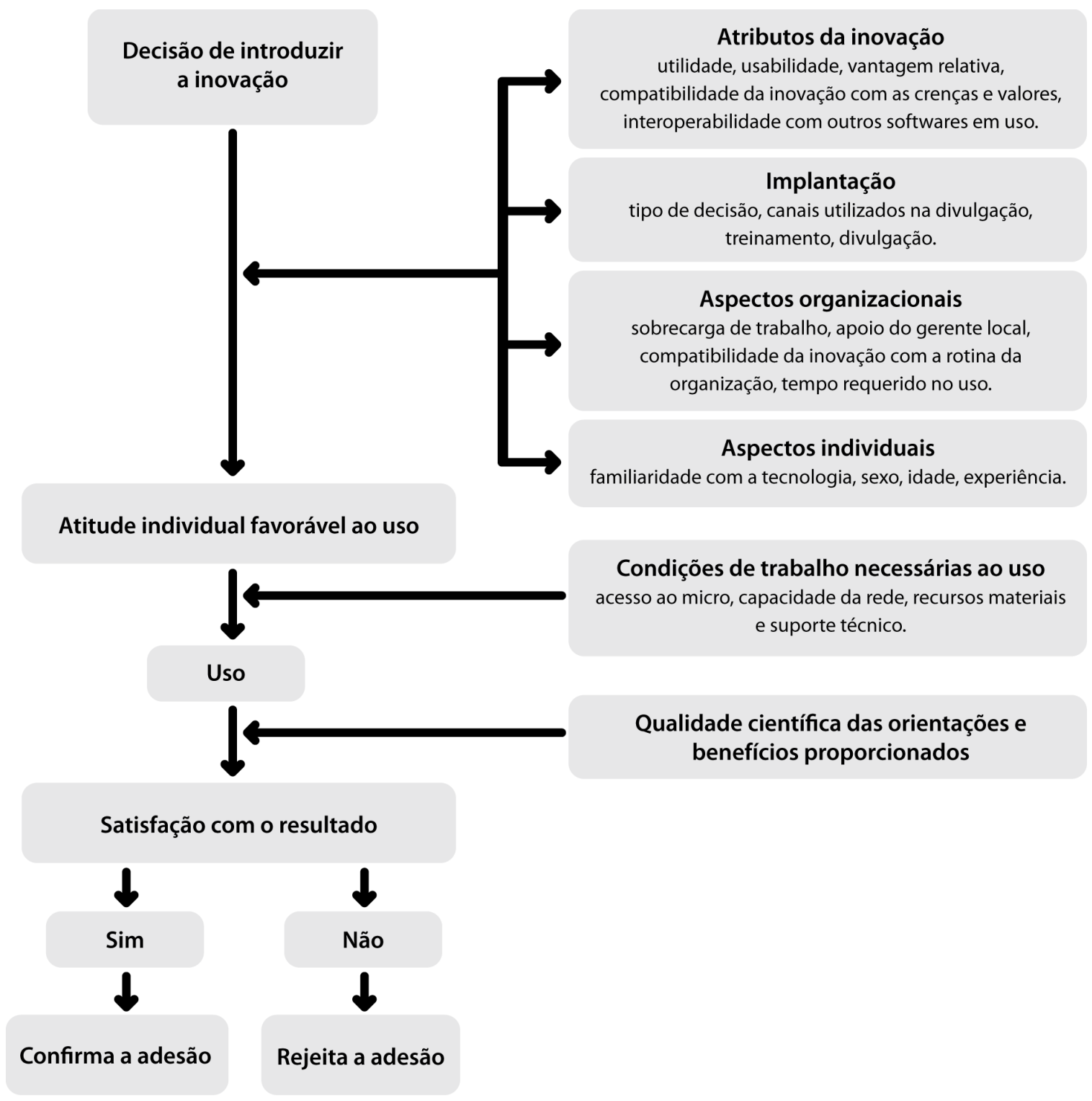

Figura 2 - Esquema representativo do modelo explicativo da utilização da TLC

À luz dos principais elementos do modelo explicativo (Figura 2), procedeu-se à leitura flutuante de todos os textos produzidos após a transcrição das entrevistas. Em seguida, foram identificados os trechos correspondentes a cada uma das categorias e suas respectivas subcategorias. Sucessivas leituras levaram à supressão de algumas subcategorias e inclusão de outras.

A interpretação buscou relacionar as vivências e significados elaborados pelos sujeitos às evidências da literatura.

\section{Resultados e discussão}

O tratamento e interpretação das entrevistas, como se verá a seguir, indicam facilitadores, entraves e críticas relacionadas à implantação (divulgação, comunicação, treinamento), à organização da produção dos serviços na UBS e às condições que os indivíduos encontram para operar o sistema BHTelessaúde. 
Viu-se que os atributos da tecnologia em si e as percepções individuais (sobre o sistema informático, sobre o trabalho e sobre as próprias habilidades e necessidades para desenvolver a atividade) interferem na utilização da TLC (Figura 3).
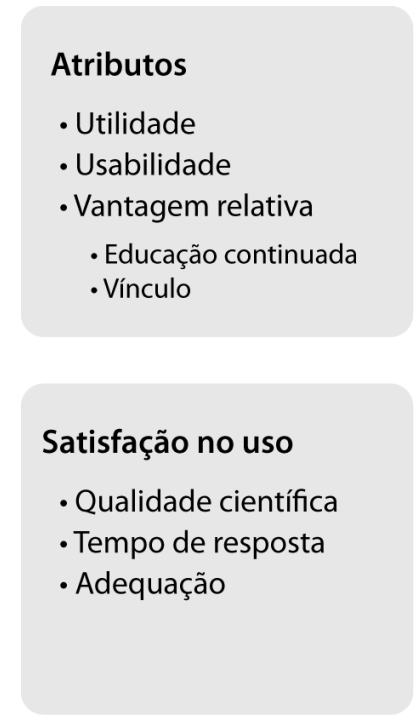

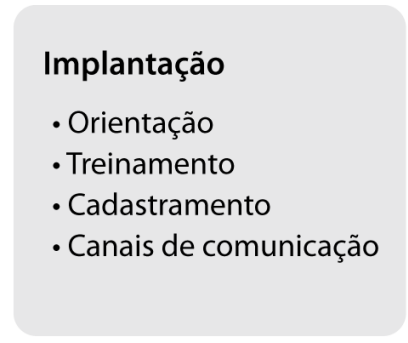

\section{Organização do serviço}

- Tempo

- Horário

- Agenda

- Estresse

- Apoio

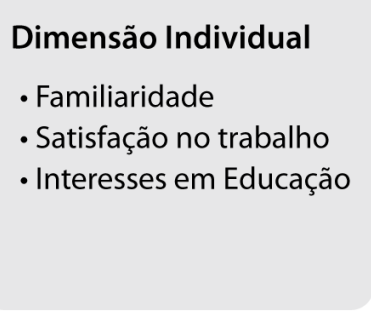

Condições de trabalho

- Computador

- Acesso

- Conexão

- Suporte

- Máquina Foto

Figura 3 - Esquema representativo das categorias e subcategorias para tratamento dos resultados

\section{Implantação}

De acordo com a Teoria da Difusão (ROGERS, 2003), os canais de comunicação pelos quais a inovação é transmitida aos indivíduos de uma organização são moduladores do grau de adesão à nova tecnologia. Estudo anteriormente realizado (RUAS, 2012) evidenciou ausência de cadastramento da totalidade dos médicos que poderiam solicitar TLC (solicitantes potenciais) no sistema BHTelessaúde, indicando possíveis debilidades no processo de implantação (divulgação, treinamento e liberação de senhas). Tal realidade é coerente com as verbalizações de três entrevistados que relataram a falta de orientações ou que manifestam dúvida quando abordados a respeito dos objetivos do serviço implantado. As expressões "eu tenho para mim" e "eu imagino" são marcas discursivas de incerteza presentes na opacidade do texto:

É, eu tenho para mim, não conheço... mas eu creio que a ideia dela é que você possa de fato evitar encaminhamentos desnecessários e tirar dúvida com os colegas (M4).

Eu sei que tem especialistas que eu imagino que são do Hospital das Clínicas, que a gente escreve a dúvida, tem um prazo para o especialista responder (M5).

Por outro lado, os entrevistados M7, M2 e M1 demonstraram conhecer os objetivos da TLC com clareza, sugerindo êxito do processo de divulgação:

[...] não falta informação, não falta entendimento dos objetivos [...] (M7).

[...] a implementação era para nos auxiliar com relação à contrarrefência, melhorar nosso acesso às especialidades, reduzir os encaminhamentos [...] (M2).

[...] quando me foi apresentado a teleconsultoria, eu achei que era uma coisa inovadora, em termos de pensar assim de qualificar o profissional da atenção primária (M1). 
As divergências discursivas "não foi orientado" e "não falta informação" permitem supor que o processo de implantação não tenha seguido um mesmo padrão para todas as UBS. Enfatiza-se que a implantação do BHTelessaúde demandou um processo de longa duração, conduzido por uma equipe que sofreu descontinuidade ao longo dos anos, conforme informações obtidas junto à SMSA ${ }^{1}$. Acrescentam-se a isso diferenças individuais na apreensão das informações divulgadas e a possibilidade de viés de memória dos entrevistados.

Em contrapartida, vários canais de comunicação foram empregados visando aumentar o alcance da divulgação: o treinamento foi individual e presencial, um manual de instruções foi enviado por email (BELO HORIZONTE, 2007), folders e cartazes de divulgação foram distribuídos para as UBS, além das oficinas de sensibilização. O entrevistado M5 é taxativo: "Inclusive eu, eu até recebi em casa um manual de como que faz teleconsultoria. Até imprimi e deixei aqui".

Quanto ao treinamento, dois sujeitos (M5 e M6) aventaram debilidades no processo de formação, contudo, a maioria dos entrevistados considera que foi suficiente:

Para mim (o treinamento) foi muito tranquilo (M1).

Um técnico de informática nos passou o básico, durante uma hora e meia, mais ou menos, como operar a ferramenta (M2).

O treinamento para operar até que foi interessante (M3)

Foi bom. O treinamento é muito simples (M4).

Acho que foi legal (M7).

Oh, o treinamento é muito fraco, eu nem sei se eu fui treinada, entendeu? (M5).

A gente foi treinada, mas muito... [...] acho que poderia ser melhor treinado, entendeu? (M6).

Os antagonismos discursivos em relação ao treinamento reforçam os indícios de descontinuidade no processo de implantação. Mas é plausível supor que também estejam relacionados aos diferentes graus de familiaridade dos sujeitos com as TICs: o mesmo treinamento pode ser suficiente para um indivíduo e insuficiente para outro que tenha menos familiaridade com a TIC. Como será visto adiante, M5 e M6 demonstraram pouca familiaridade.

\section{Organização do trabalho}

A acomodação da TLC no desenrolar da atividade depende da organização da produção na UBS e vale ainda acrescentar que a gestão do trabalho na unidade foi considerada como relevante pelos sujeitos. Entre eles, cinco $(n=7)$ expõem de forma inequívoca o esforço que a utilização da ferramenta exige em face das margens estreitas deixadas pela organização dos serviços nas UBS:

Na realidade eu não tenho um horário para a teleconsultoria não. [...] Então, no dia que está muito corrido, eu deixo de fazer [...] (M2).

\footnotetext{
${ }^{1}$ Comunicação pessoal da coordenadora de telessaúde da Gerência de Tecnologia e Informação da SMSA, Renata Trad Campos. Abril 2011.
} 
Foi dia, por exemplo, igual hoje (apontou para agenda mostrando alguns horários vazios), sobrou $[\ldots]$ (M5).

[...] a gente faz é no final de todo o atendimento, porque se não o paciente fica esperando e é desagradável, né? (M6).

[...] eu prefiro utilizar de casa mesmo, porque a forma como nosso serviço está estruturado, ele é porta-aberta (M3).

[...] não é a ferramenta de uso diário não [...] acho que a gente não consegue talvez utilizar tanto quanto poderia, em função de que você não pode mandar o caso de qualquer forma. Tem que explicar o caso e definir quais as perguntas. Isso te toma um tempo [...] que demandaria parar uma parte do serviço para isso (M4).

A tomar como base esses extratos de entrevistas reproduzidos, é possível supor que o uso da tecnologia não está contemplado no escopo de atividades da UBS. Solicitar uma TLC "toma um tempo" que demandaria "parar uma parte do serviço" que é de "porta-aberta", portanto, só é possível realizá-la eventualmente, quando "sobra" espaço na agenda ou quando não está "muito corrido".

Depreende-se do discurso dos sujeitos um possível paradoxo entre a vocação do serviço que é porta-aberta e a resolutividade, ou seja, enquanto o profissional se dedica a informar o caso ao consultor, outros usuários continuam chegando e demandam atendimento.

A pressão temporal não é fator relevante apenas no depoimento de M7. No entanto, é preciso considerar que, não ocupando a função de médico, ao contrário, exercendo a função de gerência de UBS, a posição de M7 também é constitutiva do seu discurso. No seguimento de M7, a seguir, a UBS "dá conta" da demanda, porque o "centro de saúde não é dos que têm mais movimento", entretanto, o médico precisa Ihe "pedir" para "fechar a agenda". Salienta-se novamente a não acomodação da TLC na organização do serviço:

Esse centro de saúde não é dos que têm maior movimento... a gente tem uma demanda que a gente dá conta em geral [...] se um médico me pedir fecha minha agenda mais cedo, eu vou fechar. Então, isso não é o problema. O problema é o trabalho que vai dar ficar com o caso mais difícil, mais complexo [...] É muito mais fácil [...] mandar para rede complementar (M7).

Ademais, a assertiva "o problema é o trabalho que vai dar ficar com o caso mais difícil" sugere que o encaminhamento para o nível secundário de atenção encerraria a responsabilidade da UBS pelo paciente, o que caracteriza uma contradição ao princípio de coordenação da APS. Segundo tal princípio, cabe à equipe da APS coordenar a atenção na rede de serviços indispensáveis ao cuidado dos pacientes (GIOVANELLA; MENDONÇA, 2008). Já o entrevistado M1 parece ter incorporado o princípio da coordenação e considera que a TLC o favorece, por ser "um processo de aproximação da atenção primária com a atenção secundária":

Eu acho assim, eu sou responsável pelo usuário e mesmo que eu tenha que encaminhar para o especialista, tem que dar esse retorno [...] teleconsultoria é um processo de aproximação muito grande da atenção primária com a atenção secundária (M1).

Ainda a respeito da compatibilidade da TLC com a organização do processo de trabalho, na percepção de M1 a rotina não representa explicitamente um obstáculo. Entretanto, considerando-se o modo de funcionamento do seu discurso e buscando o conteúdo latente, 
pode-se inferir que a utilização da TLC exige certo grau de voluntariedade e capacidade de regular o seu tempo. M1 declara que é "tranquilo" fazer TLC, mas acrescenta que é uma pessoa "elétrica" e "sempre acha um tempo" para as diversas atividades, mesmo que tenha que ficar na UBS "um pouco além do meu horário de trabalho":

[...] para mim é muito tranquilo [...] eu tenho o maior número de atendimentos por mês e eu ainda dou conta de fazer PEP (Programa de Educação Permanente) estudar, fazer tele, curso à distância, porque é o meu estilo de ser [...] eu sou muito assim, muito elétrica [...] eu sempre acho um tempo [...] Nem que eu tenha que ficar na unidade um pouco além do meu horário [...] Então, é entre uma consulta e outra, é no finalzinho da manhã, é paciente que faltou $[\ldots](\mathrm{M} 1)$.

Emergiu espontaneamente nas entrevistas a sobrecarga de trabalho gerando um tipo de estresse, outro fator indicado na literatura como preditor negativo de adesão à telessaúde (GAGNON et al., 2010):

Eu batalhei mais de um mês para conseguir 20 minutos para eu poder parar um pouco, tomar um café, ir ao banheiro, tomar água, porque a gente vai ficando muito... eu estava e ainda estou estressada com essa... (suspiro) de ficar de 20 em 20 minutos chamar o paciente (M1).

Nessa pressão temporal, o tempo requerido no uso da ferramenta pode estar influenciando o comportamento de se adotar ou não a TLC. Bergouht et al. (2007) mensuraram a duração de uma TLC dermatológica (11:12 minutos, em média) e concluíram que a TLC aumenta a duração da consulta. Os autores sugerem que a integração entre os sistemas de registro eletrônico dos dados do paciente e os sistemas de TLC pode otimizar o tempo requerido e favorecer a aceitação e incorporação rotineira da atividade. Vale lembrar que atualmente não há integração entre o sistema de prontuário eletrônico em uso nas UBS (SISREDE) e o sistema de teleconsultoria.

Quanto ao apoio da gestão para a utilização, sabe-se que o estímulo da gerência às mudanças e à regulamentação e institucionalização das práticas em telessaúde são fatores favoráveis à adesão (CLARK; GOODWIN, 2010). Contudo, entre os entrevistados não houve consenso a respeito do apoio da gestão:

O gerente nunca botou barreiras para acessar o sistema (M1).

A gerente anterior falou que eu poderia fazer uma teleconsultoria por mês [...] Eu acho que o interesse maior é que o médico atenda as consultas (M5).

Apesar da crença no valor da telessaúde, os usuários enfrentam dificuldades técnicas. Os entrevistados M2, M3, M5 e M6 informaram a lentidão do sistema que operacionaliza o prontuário eletrônico (SISREDE) e do sistema BHTelessaúde. A conexão disponível nas UBS é de $128 \mathrm{Kbps}$ (Kilobits por segundo) e permite operar o sistema de teleconsultorias off-line, entretanto, pode-se inferir que a mencionada lentidão no sistema de uso diário (SISREDE) seja desestimuladora da utilização das TLCs.

O suporte técnico foi citado espontaneamente no grupo entrevistado, que assume a sua importância e esclarece sobre o desempenho, muitas vezes descontínuo, conforme se vê em: 
Ontem mesmo eu [...] esqueci minha senha! [...] aí eu pensei assim, [...] vou ligar lá na Gerência de Tecnologia e Informação em Saúde (GTIS), vou pedir para eles anularem minha senha, para começar de novo (M1).

[...] Aí eu fico desesperada, alguém para me ajudar quando dá problema (M5).

A falta de recursos materiais também é citada. Os entrevistados mencionam, por exemplo, a ausência de máquina fotográfica para registrar as lesões e disponibilizá-la para o consultor: "Por exemplo, dermatologia: a gente não tem uma máquina fotográfica que fica aqui, que a gente manda muito caso para dermatologia" (M6).

\section{Atributos da inovação}

De modo geral, diante de dúvidas e incertezas no diagnóstico e conduta clínica, os sujeitos entrevistados buscam o apoio dos colegas da própria UBS, pesquisam em fontes especializadas da web ou, finalmente, lançam mãos dos dispositivos das TLCs. Dessa feita, está evidente a utilidade das TLCs porque, além de apoiar o médico da APS na condução dos casos, aprimoram o conhecimento, uma vez que a interação com o especialista em si traz elementos que permitem enriquecer o raciocínio (SANTOS; SANTOS; MELO, 2010).

A utilidade diz respeito às propriedades funcionais que tornam o software um meio eficaz para satisfazer às necessidades do usuário (GONÇALVES; FERREIRA, 2002). O extrato de entrevistas reproduzido a seguir ilustra a utilidade da TLC para o processo de trabalho na APS:

Em geral, a gente tenta discutir primeiro com os colegas que estão aqui próximos, no Centro de Saúde $[\ldots]$ (M4).

[...] aí eu vou buscar então os guidelines, eu faço uma revisão no PubMed, Scielo, [...] Up to Date (M3).

[...] em alguns momentos [...] que eu acho que vale a pena ver a opinião do especialista eu faço a tele [...] Eu aprendi muita coisa com a tele e hoje, $[\ldots]$ eu encaminho muito menos para o especialista do que eu encaminhava quando eu comecei na saúde da família (M1).

O trabalho em equipe é essencial para se alcançar a integralidade da atenção na estratégia saúde da família (ESF). Segundo Araújo e Rocha (2007, p. 456), "a ação interdisciplinar pressupõe a possibilidade da prática de um profissional se reconstruir na prática de outro, ambos sendo transformados para a intervenção na realidade em que estão inseridos".

É importante ressaltar que três entrevistados (M5, M6 e M7), apesar de utilizarem a TLC, não se referiram a ela como uma alternativa para lidar com os casos clínicos. O entrevistado M4 relata que nem sempre acontece de pensar na disponibilidade da TLC ("Muitas vezes eu me recrimino por não usar tanto quanto poderia $\left.[\ldots]^{\prime \prime}\right)$. Tais resultados são convergentes com a literatura: $30 \%$ dos 56 médicos de saúde da família não utilizaram ou se esqueceram de utilizar os dispositivos, apesar de garantido o acesso a um serviço de teleconsultorias por videoconferência (ANGSTMAN et al., 2009). Quanto a esse comportamento, os entrevistados são claros:

Discuto com colegas, às vezes pego meu celular [...] (M5).

[...] o que a gente já tem culturalmente é a questão de encaminhar para a atenção secundária, né? (M7). 
A usabilidade de um software diz respeito ao conjunto de atributos de um sistema relacionados ao esforço necessário para a sua operação (GONÇALVES; FERREIRA, 2002), ou seja, a percepção de facilidade no uso (SANTOS, 2004). Os entrevistados (5/7) consideram o sistema BHTelessaúde de fácil manejo.

Apenas um respondente (M5) mencionou dificuldade para operar o sistema. Segundo ele, é "um sistema meio complicado para a gente conseguir, sabe?" Contudo, como afirmado anteriormente, a acomodação do aparato tecnológico pela organização parece exercer algum papel na percepção de usabilidade e na utilização da ferramenta, conforme se vê no depoimento de M5: "[...] teleconsultoria assim para gente é muito difícil. Que a gente tem um número de consultas para atender cada dia [...] Então eu acho que o problema maior é a falta de tempo. E um modelo simplificado".

Estudo anterior (BARROS; CARDOSO, 2008) na Secretaria Municipal de Saúde (SMSA) para teleconsultorias off-line, teleconsultorias on-line e videoconferências encontrou resultados semelhantes: os usuários reconhecem a utilidade das modalidades de telessaúde implantadas, consideram os sistemas de fácil manejo, demonstram interesse em participar, mas enfrentam dificuldades para conciliar as diversas tarefas do cotidiano com as inovações propostas.

Vantagem relativa é a percepção individual de vantagens da inovação em relação às tecnologias ou práticas vigentes (SANTOS, 2004). Na opinião dos entrevistados, a discussão do caso clínico com o consultor propicia a incorporação de conhecimento, o que nem sempre ocorre quando se faz o encaminhamento do paciente para o nível secundário de atenção. A TLC transforma a experiência do especialista em conhecimento aplicável para a resolução de problemas reais, constituindo-se em estratégia de educação continuada focada no contexto do médico solicitante (WEN, 2008). Os depoimentos a seguir indicam que a educação continuada representa uma vantagem relativa da TLC:

[...] a vantagem é educação continuada... porque quando eu mando para ele (especialista), ele fica com o caso, às vezes ele não manda de volta, aí eu não aprendo nada com ele e com a tele eu aprendo (M1).

[...] a contrarreferência ela não vem direcionada para nossas dúvidas, isso quando vem, porque geralmente ela não ocorre [...] (M2).

Ressalta-se o valor da TLC em fortalecer o vínculo entre o paciente e a equipe que o atende:

Mantém o vínculo com o paciente, porque todos os momentos que eu mando o paciente para o especialista, a impressão que me dá é que [...] ele cai num buraco negro [...] para marcar o retorno é difícil demais, e o caso fica [...] restrito lá, ao especialista (M4).

[...] O paciente [...] tem uma vinculação comigo, coisa que ele não tem com o especialista. Então, se eu discutir com o especialista e o especialista me disser "não, isso aí tranquilo, isso não é nada", eu acho que aquela fala minha com o paciente [...] é mais sustentada do que se ele vai para o especialista que não tem aquele vínculo [...] o paciente se sente confortável porque ele tem essa vinculação comigo (M1).

A integralidade do cuidado e a responsabilidade longitudinal pelo paciente ao longo da vida são atributos da APS que contribuem para o estabelecimento do vínculo e, portanto, para uma relação mais humanizada e corresponsável (GIOVANELLA; MENDONÇA, 2008; SANTOS; SOARES; CAMPOS, 2007). Analisando-se os depoimentos, seria plausível supor que a 
utilização da teleconsultoria off line é influenciada pelo grau de implicação do médico com os objetivos do novo modelo assistencial, e não exclusivamente pela facilidade em manejar a ferramenta. Tal observação caracteriza uma possível particularidade da TLC em relação a outras inovações.

\section{Satisfação e familiaridade com TIC}

Em relação aos resultados alcançados no uso da TLC, os médicos entrevistados relatam tanto experiências positivas quanto negativas. Espontaneamente, o grupo abordou três aspectos: qualidade da orientação recebida, adequação da resposta à pergunta e tempo de resposta.

Quanto à percepção de qualidade científica da resposta do teleconsultor, há tanto avaliações positivas quanto negativas:

[...] a última tele que eu fiz na otorrino, ele me mandou uma referência para eu estudar eu achei tudo de bom! (M1)

Tem alguns profissionais que eu fiquei encantada com o jeito que eles responderam (M2).

Todas as respostas foram muito bem utilizadas (M3).

[...] eu tive algumas respostas fantásticas [...] isso me ajudou em vários outros casos. Ao mesmo tempo (eu tive) respostas de pessoas que [...] responderam qualquer coisa, que precisam de dados que não tinham nada a ver com a situação [...] (M4).

A consultoria que fiz na gastroenterologia eu acho que foi satisfatória. Agora a teleconsultoria que eu fiz sobre criança albina [...] eu achei muito superficial, sabe? (M5).

Divergências também estão presentes em relação à percepção de adequação da resposta à pergunta. Enquanto o entrevistado M1 valoriza a resposta completa e o envio de referências bibliográficas, "ele mandou uma referência para eu estudar, eu achei tudo de bom", M4 espera uma resposta direta e resumida:

[...] algumas resposta [...] não funcionam também [...] porque você pede uma dúvida e a pessoa te traz um milhão de referências [...] a pessoa me mandou quase oito páginas [...] Eu não quero isso... [...] Aí eu mandei para um outro que aí sim [...] com três linhas a pessoa respondeu o que eu queria saber (M4).

No BHTelessaúde, a resposta do especialista é emitida em texto livre. Os generalistas, em Singapura, preferem receber a contrarreferência do especialista em formato estruturado (THONG; MOK; LOKE, 2010). A pesquisa, conduzida com o objetivo de melhorar a comunicação entre APS e os serviços de atenção especializada, testou dois modelos de contrarreferências (texto livre e estruturado), ambos com o mesmo número de informações. No conjunto, 96\% dos 535 generalistas envolvidos no estudo consideraram que o formato estruturado era de leitura mais rápida e continha mais informações.

A SMSA preconiza que a resposta do especialista se dê em até 72 horas, entretanto, os depoimentos indicam que nem sempre o teleconsultor envia as orientações dentro do prazo recomendado:

A nossa expectativa era de conseguir a resposta antes do retorno do paciente e algumas vezes não consegui isso (M2). 
Um (especialista) demorou a responder uma vez que eu mandei para ele. Aí teve um outro que eu mandei, respondeu rápido (M4).

A familiaridade com TIC pode influenciar na adesão às inovações tecnológicas (GAGNON et al., 2010). No grupo entrevistado, a maioria considera o uso de TIC familiar, entretanto, M6 afirma que "é familiar, mas eu não gosto não". M5 esclarece: "Porque antes eu não gostava de computador não. Agora eu dependo de computador." Vê-se que M5 e M6 consideraram o treinamento deficiente e são solicitantes eventuais (duas a quatro TLCs no período avaliado).

Outra característica que se refere à dimensão individual é o interesse pela educação continuada. Tal característica pessoal não é surpreendente, uma vez que a TLC se configura como uma estratégia de educação continuada e, sob autonomia para o uso, requer interesse do profissional. O depoimento a seguir é esclarecedor: "[...] a gente tem que ter a prioridade da educação continuada, porque se não a gente para no tempo e a gente fica velho. A gente não é igual o vinho que fica bom. A gente fica ruim se a gente não estudar" (M1).

Para Rebouças et al. (2009, p. 625) a satisfação no trabalho pode ser entendida como "o sentimento resultante da interação de profissionais com suas crenças e valores e o ambiente de trabalho; e o impacto que este produz na saúde e o bem-estar dos profissionais". A satisfação no trabalho é um elemento da dimensão individual que emergiu durante as entrevistas, positivamente para M1 e negativamente para M5. Vale lembrar que M1 é um "solicitante frequente" (114 TLCs no período do estudo) e M5 um "solicitante eventual". Interessante observar que M5 associa a insatisfação no trabalho com a não utilização do serviço de TLC.

Eu sou muito feliz com o que eu faço porque medicina era um sonho de criança, sabe? Gosto do eu faço, venho para cá satisfeita e volto para casa satisfeita (M1).

Todos os meus colegas estão insatisfeitos [...] A equipe, nós somos 4 [...] só eu fiz teleconsultoria (M5).

\section{A guisa de conclusão}

Várias vantagens da utilização da TLC foram mencionadas pelos sujeitos. De modo geral, a TLC é de fácil utilização, promove o aperfeiçoamento e reforça o vínculo médico-paciente.

A utilidade das TLCs também foi reconhecida na Malásia, onde a maioria dos usuários indica as seguintes vantagens da ferramenta: facilita o acesso rápido ao especialista, amplia o leque de especialistas para interação, melhora o acervo documental, melhora a coordenação entre os hospitais implicados no manejo do paciente, melhora a comunicação entre o médico e consultor e aperfeiçoa o processo de aprendizagem dos médicos (MAAROP et al., 2001). Também em áreas remotas de Québec, os médicos e os gestores afirmam que a telessaúde facilita o acesso dos profissionais aos serviços especializados, favorece a continuidade dos cuidados, contribui para o aperfeiçoamento da prática dos médicos, facilitando a educação médica continuada e o acesso a uma segunda opinião (GAGNON et al., 2006).

No entanto, depreende-se do discurso dos sujeitos o caráter multifacetado da decisão de se adotar a TLC. Aspectos organizacionais, condições de trabalho, atributos da tecnologia e as dimensões individuais podem estar agindo na decisão dos sujeitos para inserir a tecnologia no bojo de sua a atividade (Figura 3). Tais resultados são convergentes com a literatura. Viu-se, à 
semelhança das descrições de Gagnon et al. (2010), que os entraves (sobrecarga de trabalho, debilidades no treinamento e pouca familiaridade do profissional com a informática) interagem entre si (como indicam os antagonismos discursivos) para influenciar a decisão de utilização.

Entre as condições de trabalho necessárias ao uso, a qualidade da conexão (lentidão) é desmotivadora e fator anteriormente identificado pelos autores (BARROS; CARDOSO, 2008; HADAD et al., 2010). De maneira similar, dificuldade na acomodação do uso da TLC à estrutura organizacional vigente permanece como um obstáculo à sua consolidação, convergindo mais uma vez com os estudos anteriores (BARROS; CARDOSO, 2008; HADAD et al., 2010). Vale lembrar que, para a OPAS (2010, p. 5), o sucesso da referida estratégia depende de "investimento considerável de recursos e a superação progressiva de problemas de cultura institucional e de conectividade".

Gagnon et al. (2003) referiram que os médicos engajados em suas responsabilidades profissionais e sociais foram mais susceptíveis à adoção da telessaúde em sua prática. Há riscos quando se concebe tais ferramentas sem incorporar as necessidades e as características dos usuários na execução de tarefas especificas (ABRAHÃO; SILVINO; SARMET, 2005). As inovações que empregam TIC interferem na evolução das relações sociais, empregos e ocupações. Elas provocam uma série de transformações sobre o conteúdo das tarefas e sobre as estratégias da organização do trabalho, formas de gestão, formas de consulta e negociação (BRAMI ; LOMBRAIL; ROQUELAURE, 2006). A introdução de uma nova tecnologia desafia a estrutura organizacional vigente e os fatores operacionais. Dessa feita, são requeridos ajustes mútuos, da organização e da própria tecnologia (GAGNON et al., 2006).

Não seria excessivo afirmar que, em face do atual arranjo organizado pela gestão dos serviços, a TLC torna-se uma atividade extra e dependente da "capacidade" do profissional em embutir o manejo da ferramenta na sua rotina (ou de conseguir realizar tarefas simultâneas), como sinaliza o discurso de M1. A segunda opinião não está prevista na estrutura organizacional, portanto, não se trata de incorporar recursos tecnológicos em uma prática existente, mas de inaugurar uma nova prática de gestão do trabalho tendo em vista o modelo da assistência e seu intuito de se alcançar a integralidade e a coordenação do cuidado (SANTOS; SANTOS; MELO, 2010).

A assertiva "é muito mais fácil mandar para rede complementar" sugere que tal propósito não tenha sido ainda completamente assimilado pela gestão. Estaria a TLC sendo encarada como dispositivo meramente substitutivo do encaminhamento para o especialista, representando, assim, uma transferência de atribuições do nível secundário para a UBS?

A TIC, ao responder às necessidades dos sistemas e das políticas de saúde, também provoca alterações substanciais nos processos de trabalho e nas práticas do cuidado. As interações dos profissionais de saúde são multiplicadas, requerendo evolução da gestão dos sistemas e da gestão do trabalho (ASSUNÇÃO; JACKSON FILHO, 2001).

No entanto, é provável que a implantação das novas tecnologias se desenvolva abstraindo-se das condições de produção dos serviços, ou seja, desconsiderando-se o exercício do trabalho real.

O ato de buscar uma opinião de um consultor à distância também representa um desarranjo no arquétipo tradicional da relação médico-paciente. Existe um tensionamento entre a 
reconhecida autonomia médica e as políticas que orientam a práticas de trabalho multiprofissional e interdisciplinar (PEDUZZI, 2002). Ora, a formação médica está menos voltada para o compartilhamento do ato do que para a relação solitária médico-paciente. A ruptura com o modelo hegemônico requer redimensionamento da autonomia médica e melhor qualificação profissional, tanto na dimensão técnica, quanto na dimensão comunicacional e inter-relacional.

Ressalta-se o potencial da socialização do conhecimento nas redes interpessoais para levantar barreiras à utilização e promover mudanças de significado (TRINDADE, 2008). O presente estudo não permite aprofundar tais questões, mas possibilita a identificação de médicos usuários líderes da inovação implantada que poderão contribuir para a mobilização de habilidades e atitudes favoráveis à utilização da TLC pelos seus colegas.

Sabe-se que o sucesso da telemedicina requer reestruturação de procedimentos tradicionais dos serviços de saúde (MARTINEZ, 2000) e que mudar a rotina de médicos implica ruptura das crenças e dos padrões preestabelecidos de fluxos de trabalho (BARTON et al., 2007). As mutações dos sistemas de saúde articuladas às reformas sanitárias e as políticas de saúde para todos enfrentam a lógica do complexo médico-industrial (forte dependência de exames e imagens, e lógica hospitalocêntrica) que continua embasando a formação dos médicos. Seriam esperadas barreiras que explicam a baixa taxa de adoção das TLCs na SMSA-BH, cujo modelo assistencial é calcado na interação, nas redes e no conhecimento (FERREIRA; SILVA; AGUERA, 2007). Enfim, a TLC desafia o paradigma dominante que orienta a prática assistencial.

Para Franco e Merry (1999), quando se pretende uma mudança de modelo, é preciso prever dispositivos que mudem os processos de trabalho em saúde. A efetividade da Telemedicina está associada a planos estratégicos, visando a elegê-la como prática exclusiva e valiosa no processo de logística de distribuição de serviços (WEN, 2008).

Alguns limites da presente pesquisa devem ser mencionados, entre eles aqueles já esperados quando se emprega a técnica da entrevista aberta. A interação entre entrevistado e entrevistador é tensa, porque a visão de mundo de ambos está implicada no processo de conhecimento, sendo difícil reduzir as distorções geradas nas interpretações do pesquisador envolvido. Ainda assim, vale ressaltar que durante a análise o pesquisador buscou contemplar os processos de produção dos sentidos e evitar interferência nas conclusões (GOLDENBERG, 2007). No entanto, é possível a ocorrência de vieses de interpretação.

Os modelos teóricos empregados e a abordagem qualitativa permitiram aproximar-se de uma realidade ainda não bem explorada em estudos brasileiros e trouxe à tona os significados para os sujeitos das práticas que envolvem a telessaúde. Os resultados convergem aos estudos qualitativos realizados no Quebec (GAGNON et al., 2006) e na Malásia (MAAROP et al., 2001). A referência aos estudos mencionados e às evidências tratadas anteriormente pode embasar 0 delineamento de futuros estudos, sobretudo contribuir para a elaboração de projetos de implantação e consolidação da telessaúde.

Em síntese, os médicos solicitantes afirmam o potencial e a pertinência da TLC para a APS e as contradições encontradas sugerem pistas para orientar a gestão em suas ações, visando à consolidação do sistema. 


\section{Referências}

ABRAHÃO, J. I.; SILVINO, A. M. D.; SARMET, M. M. Ergonomia, cognição e trabalho informatizado. Psic. Teor. e Pesq., v. 21, n. 2, p. 163-171, 2005.

ANGSTMAN, K .B. et al. Provider satisfaction with virtual specialist consultation in a family medicine department. Health Care Mang, v. 28, n. 1, p. 14-8, 2009. Disponível em: <http://www.ncbi.nlm.nih.gov/pubmed/19225331>. Acesso em: jan 2012.

ARAÚJO, M. B. S.; ROCHA, P. M. Trabalho em equipe: um desafio para a consolidação da estratégia da saúde da família. Ciência e Saúde Coletiva, Rio de Janeiro, v. 12, n. 2, p. 455-464, 2007. Disponível em: <http://www.scielosp.org/scielo.php?pid=S1413-

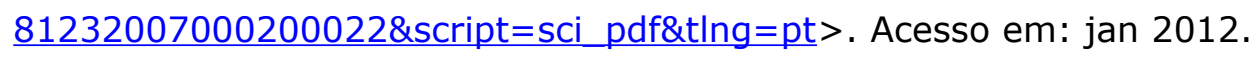

ASSUNÇÃO, A. A.; JACKSON FILHO, J. M. Transformações do trabalho no setor saúde e condições para cuidar. In: ASSUNÇÃO, A. A.; BRITO J. Trabalhar na saúde: experiências cotidianas e desafios para a gestão do trabalho e do emprego. Rio de Janeiro: Editora Fiocruz, 2011.

BARDIN, L. Análise de Conteúdo. Lisboa: Edições70, 1977.

BARROS, K. A. A. L.; CARDOSO, A. M. P. Avaliação da usabilidade dos sistemas de teleconsultoria médica usados na atenção primária em Belo Horizonte. Textos de la Cibersociedad, n. 16, 2008. Disponível em: <http//www.cibersociedad.net>. Acesso em: out 2011.

BARTON, P.L. et al. Specialist physicians' knowledge and beliefs about telemedicine: a comparison of users and nonusers of the technology. Telemed J. E. Health, v. 13, n. 5, p. 487-99, 2007.

BELO HORIZONTE (MG). Secretaria Municipal de Saúde. Manual de operações do sistema BHTelessaúde. Belo Horizonte, MG, 2007.

BERGOUHT, R. M. et al. Evaluation of general practitioner's time investment during a storeand-forward teledermatology consultation. Int J Inform, v. 76. sup. 3, p. 384-91, 2007. Disponível em: <http//www.ncbi.nlm.nih.gov/pubmed?term=\%20referral\%20primary\%20care \%20specialiyt\%20comunication. > Acesso em: out 2011.

BRAMI, L.; LOMBRAIL, P.; ROQUELAURE, Y. La gestion des risques à I'hôpital, une opportunité de coopération entre qualiticiens et ergonomes pour les conditions de travail des personnels hospitaliers. In: CONGRES DE LA SOCIETE D'ERGONOMIE DE LANGUE FRANÇAISE, 41., 2006, Caen. Actes... Caen: SELF,2006. p. 209-216. Disponível em: <http://www.ergonomieself.org/documents/41eme-Caen-2006/session2.pdf>. Acesso em: jan de 2012.

BRASIL. Ministério da Saúde. Secretaria de Atenção à Saúde. Departamento de atenção Básica. Política Nacional de Atenção Básica. Brasília, DF, 2006. (Série Pactos pela Saúde). Disponível em: http://www.saude.gov.br/ pactos pela saude.htm. Acesso em: jan. 2012.

CAREgNATO, R. C. A.; MUTTI, R. Pesquisa qualitativa: análise do discurso versus análise de conteúdo. Texto Contexto Enferm, v.15, n.4, p. 679-84, 2006. 
CLARK, M.; GOODWIN, N. Sustaining innovation in telehealth and telecare. WSDAN briefing paper. London: WSD Action Network, 2010. Disponível em: <http://www.technologyadoptionhub.nhs.uk/assets/ files/documents/apr_10/nhs

1271416227 Organisational and Behavioural.pdf. >. Acesso em: abr. 2011.

DAVIS, F.D. Perceived usefulness, perceived ease of use and user acceptance of information technology. MIS Quarterly, v.13, n.3, p. 319-340, 1989.

GAGNON, M.P. et al. An adaptation of the theory of interpersonal behaviour to the study of telemedicine adoption by physicians. Int. J. Med. Inf., v. 71, p. 103-115, 2003.

GAGNON, M.P. et al. Implementing telehealth to support medical practice in rural/ remote regions: what are the conditions for success? Implement Sci., v. 1, p. 18, 2006.

GAGNON, M.P. et al. Systematic review of factors influencing the adoption of information and Communication technologies by healthcare professionals. J. Med. Syst., v. 36, p.241-77, 2010.

GAGNON, M.P. et al. Telehealth adoption in hospitals: an organizational perspective. J. Health Organ. Manag., v. 19, n. 1, p. 32-56, 2005.

GÉRVAS, J.; ORTÚN, V. Caracterización del trabajo asistencial del médico general/de familia.

Atencion Primaria, v. 16, n. 8, p. 501-06. 1995. Disponível em: $<$ http://www.econ.upf.edu/ ortun/publicacions/AtPrim 95.pdf> Acesso em: jan. 2012.

GIOVANELLA, L.; MENDONÇA, M. H. M. Atenção primária à saúde. In: GIOVANELLA, L. et al. (Org.). Políticas e sistema de saúde no Brasil. Rio de Janeiro: Editora Fiocruz, 2008.

GOLDENBERG, M. A arte de pesquisar: como fazer pesquisa qualitativa em ciências sociais. Rio de Janeiro: Record, 2007.

GONÇALVES, R. M.; FERREIRA, M. C. Ergonomia do serviço de atendimento ao público via internet: utilidade e usabilidade de web sites para os usuários. 2002. Dissertação (Mestrado) - Universidade Federal de Brasília, Brasília, DF, 2002. Disponível em: <http://ergopublic.com.br/arquivos/1252865131. 27-arquivo.pdf>. Acesso em: 1 maio 2011.

HADAD, S. et al. Evaluación cualitativa de teleconsultoria del sistema BH-Telessaúde desde la perspectiva de médico. Revistae Salud.com, v. 6, n. 24, 2010. Disponível em: <http://www.revistaesalud.com>. Acesso em: 1 out. 2011.

KARAHANNA, E.; STRAUB, D. W.; CHERVANY, N. L. Information technology adoption across time: a cross-sectional comparison of pre-adoption and post-adoption beliefs. MIS Quarterly, v. 23, n. 2, p. 183-213, 1999.

LÜDKE, M.; ANDRÉ, M. Pesquisa em educação: abordagens qualitativas. São Paulo: EPU, 1986.

MAAROP, N. et al. Exploring factors that affect teleconsultation adoption: in the case of Malaysia" pacis. Proceedings, 2001. Paper 124. Disponível em: <http://aisel.aisnet.org/pacis2011/124>. Acesso em: jan. 2012. 
MACHADO, M. N. M. Entrevista de pesquisa: a interação pesquisador/ entrevistado. Belo Horizonte: C/Arte, 2002.

MARTINEZ, A. Bases metodológicas para evaluar la viabilidad yel impacto de proyectos de telemedicina. Madrid: Universidad Politécnica de Madrid, 2000. Disponível em: <http://www.scribd.com/doc/12722087/Bases-Metodologicas-para-Evaluar-la-Viabilidad-y-elImpacto-de-Proyectos-de-Telemedicina > . Acesso em: abr 2010.

ORGANIZAÇÃO PAN-AMERICANA DA SAÚDE. Estratégia para o desenvolvimento de competências dos profissionais de saúde nos sistemas de saúde baseados na Atenção Primária. Washington, DC, $50^{\circ}$ Conselho Diretor, $62^{\circ}$ Sessão do comitê regional, 2010. Disponível em: <http://new.paho.org/hq/dmdocuments/2010/CD50-11-p.pdf> Acesso em: jan. 2012.

PEDUZZI, M. Mudanças tecnológicas e seu impacto no processo de trabalho em saúde. Trabalho Educação e Saúde, v. 1, n. 1, p. 75-91, 2010.

REBOUÇAS, D. et al. O trabalho em saúde mental: um estudo de satisfação e impacto. Cad. Saúde Pública, Rio de Janeiro, v. 24, n. 3, p. 624-32, 2009. Disponível em: $<$ www.scielo.br/pdf/csp/v24n3/16.pdf>. Acesso em: jan 2012.

ROGERS, M.E. Diffusion of Innovation. 5. ed. New York: Free Pass, 2003.

RUAS, S. S. M. Teleconsultoria na atenção primária de Belo Horizonte: desafios na difusão de uma inovação. 2012. Dissertação (Mestrado) - Programa de Pós-Graduação em Saúde Pública, Faculdade de Medicina da Universidade Federal de Minas Gerais, Belo Horizonte, 2012.

SANTOS, L. D. Fatores determinantes do sucesso de serviços de informação online em um sistema de gestão de ciência e tecnologia. 2004. Tese (Doutorado) - Escola de Engenharia, Universidade do Minho, Guimarães, PT, 2004. Disponível em: <http://repositorium.sdum.uminho.pt/handle/1822/2281>. Acesso em: abr 2011.

SANTOS, A. F. et. al. Incorporação de recursos de telessaúde na atenção primária. In: MAGALHÃES JÚNIOR, H. M. (Org.) Desafios e inovações na gestão do sus em Belo Horizonte: a experiência de 2003 a 2008. Belo Horizonte: Mazza, 2010.

SANTOS, V. C.; SOARES, C. B.; CAMPOS, C. M. S. A relação trabalho-saúde de enfermeiros do PSF no município de São Paulo. Ver. Esc. Enferm. USP, v. 41, p. 771-81, 2007. Disponível em: <www.ee.usp.br/reeusp >. Acesso em: jan 2012.

THONG, J. F.; MOK, P.; LOKE, D. A quality assurance survey to improve communication between ENT specialists and general practitioners. Med. J., Singapore, v. 51, n. 10, p. 796-9, 2010. Disponível em: <http://www.ncbi.nlm.nih.gov/pubmed/21103815>. Acesso em: jan 2012.

TRINDADE, E. A incorporação de novas tecnologias nos serviços de saúde: o desafio da análise dos fatores em jogo. Cad. Saúde Pública, Rio de Janeiro, v. 24, n. 5, p. 951-964, 2008. Disponível em <http//www.scielosp.org>. Acesso em: jan. 2012.

TRIVIÑOS, A. N. S. Introdução à pesquisa em ciências sociais. São Paulo: Atlas, 1987. 
TURATO, E. R. Tratado da metodologia da pesquisa clínico-quantitativa: construção teórico-epistemológica, discussão comparada e aplicação nas áreas de saúde e humanas. Petrópolis: Vozes, 2003.

WEN, C. L. Telemedicina e telessaúde: um panorama no Brasil. Informática Pública, v. 10, n. 2, p. 7-15, 2008. Disponível em: <http://www.ip.pbh.gov.br/ ANO10 N2 PDF/telemedicina telesaude.pdf>. Acesso em: jan 2012.

YARBROGH, A. K.; SMITH, T. B. Technology acceptance among physicians. Medical Care Research and Review, v. 64, p. 650-672, 2007.

Recebido 10.06 .12

Aceito 01.08.2012 